\title{
Parametric effects on the combustion flow field of a typical strut-based scramjet combustor
}

\author{
HUANG Wei ${ }^{1,2 *}$, WANG ZhenGuo ${ }^{1}$, LUO ShiBin $^{1} \&$ LIU Jun ${ }^{1}$ \\ ${ }^{1}$ College of Aerospace and Materials Engineering, National University of Defense Technology, Changsha 410073, China; \\ ${ }^{2}$ Centre for CFD, School of Process, Environmental and Materials Engineering, University of Leeds, LS2 9JT, United Kingdom
}

Received November 19, 2010; accepted March 24, 2011

\begin{abstract}
The flame-holding mechanism in hypersonic propulsion technology is the most important factor in prolonging the duration time of hypersonic vehicles. The two-dimensional coupled implicit Reynolds-averaged Navier-Stokes equations, the shear-stress transport $k$ - $\omega$ turbulence model and the finite-rate/eddy-dissipation reaction models were used to simulate the combustion flow field of a typical strut-based scramjet combustor. We investigated the effects of the hydrogen-air reaction mechanism and fuel injection temperature and pressure on the parametric distributions in the combustor. The numerical results show qualitative agreement with the experimental data. The hydrogen-air reaction mechanism makes only a slight difference in parametric distributions along the walls of the combustor, and the expansion waves and shock waves exist in the combustor simultaneously. Furthermore, the expansion wave is formed ahead of the shock wave. A transition occurs from the shock wave to the normal shock wave when the injection pressure or temperature increases, and the reaction zone becomes broader. When the injection pressure and temperature both increase, the waves are pushed out of the combustor with subsonic flows. When the waves are generated ahead of the strut, the separation zone is formed in double near the walls of the combustor because of the interaction of the shock wave and the boundary layer. The separation zone becomes smaller and disappears with the disappearance of the shock wave. Because of the horizontal fuel injection, the vorticity is generated near the base face of the strut, and this region is the main origin for turbulent combustion.
\end{abstract}

aerospace propulsion systems, strut, scramjet combustor, combustion flow field, computational fluid dynamics, hydrogenair reaction mechanism

Citation: Huang W, Wang Z G, Luo S B, et al. Parametric effects on the combustion flow field of a typical strut-based scramjet combustor. Chinese Sci Bull, 2011, 56: 3871-3877, doi: $10.1007 / \mathrm{s} 11434-011-4823-2$

With the success of the Hyper-X program [1] and the first flight test of the X-51A on May 26, 2010 [2], hypersonic propulsion technology has drawn increasing attention from researchers. However, the flame-holding mechanism in the scramjet combustor cannot satisfy the requirement for cruising a long time in near-space [3] because of the short residence time of the mixture remaining in the supersonic flow, which is in the order of milliseconds [4]. This restricts improvement of the aerodynamic performance of hypersonic vehicles. To solve this problem, some fuel injection techniques have been proposed. The strut [5-14], the cavity

*Corresponding author (email: gladrain2001@yahoo.com.cn)
[15-18], the cantilevered ramp [4], the backward facing step [19-21] and the combination [22-25], whose principle is to generate vorticity in the vicinity of the walls of the combustor. The region forming the vorticity, namely the recirculation zone, has low flow velocity. In this region the fuel mixes with the supersonic flow and the mixture can stay in the scramjet combustor for a long time.

Zou et al. [6] have used a newly-proposed partiallyresolved numerical simulation procedure to investigate turbulent combustion in a two-dimensional DLR scramjet engine, and the large-scale turbulence was defined by the temporal filtering. Oevermann [7] has used a two-equation $k$ - $\varepsilon$ turbulence model combined with a stretched laminar 
flamelet model to simulate the turbulent diffusion flames in a strut-based scramjet combustor. The commercial software Fluent has been applied to study the mixing and combustion characteristics of kerosene in a strut-based full-scale supersonic combustor along with the single-step laminar finiterate kinetics, with calculations performed using the oneequation Spalart-Allmaras model [8]. Furthermore, a largeeddy simulation has been used to simulate the flow field downstream of a three-dimensional strut-based injection system in a scramjet combustor $[9,10]$. Three different hydrogen-air reaction mechanisms have been introduced to perform the turbulent combustion simulation, namely the one-, two- and seven-step mechanisms [11].

Recently, Luo et al. [12] investigated the influence of the turbulence models on the flow field in a typical strut-based scramjet combustor, and they found that the RNG $k-\varepsilon$ model showed better agreement with the experimental data than the realizable $k-\varepsilon$ model and SST $k$ - $\omega$ model in the nonreacting flow field. The numerical results obtained by the three turbulence models all show reasonable agreement with the experimental data.

However, the effects of the fuel injection temperature and pressure on the combustion flow field and parametric distributions in the strut-based scramjet combustor are rarely investigated, and the turbulent combustion in the boundary layer is not clear.

In this paper, we use the two-dimensional coupled implicit Reynolds-averaged Navier-Stokes (RANS) equations, the shear-stress transport (SST) $k$ - $\omega$ turbulence model and the finite-rate/eddy-dissipation reaction models to investigate the combustion flow field in the strut-based scramjet combustor. The effects of the injection pressure and temperature on shock wave structure are primarily discussed. At the same time, we introduce two different hydrogen-air reaction mechanisms, namely the one- and two-step mechanisms, to analyze the combustion flow field of the combustor under the reference boundary condition.

\section{Physical model and numerical method}

The geometric model used in this paper is based on a typical strut-based scramjet combustor, which was tested at the German Aerospace Center, Stuttgart [5,7,9,10,12] (Figure 1). Preheated air is expanded through a Laval nozzle and enters the combustor at Mach 2.0 [10]. The combustor has a length of $340 \mathrm{~mm}$ and a height of $50 \mathrm{~mm}$ at the entrance. From $X=-9 \mathrm{~mm}$ on, the upper wall of the combustor diverges with a constant angle of $3^{\circ}$ to compensate for the boundary layer growth. A strut is placed at the centerline, namely $Y=25 \mathrm{~mm}$. The length of the strut is $32 \mathrm{~mm}$, and its half-angle is $6^{\circ}$. Hydrogen is injected horizontally from the center of the strut base with local sonic velocity. The strut base is located at $X=0$, and the width of the injection slot is $1 \mathrm{~mm}$.

The static pressure and temperature of the supersonic inflow are $100000 \mathrm{~Pa}$ and $340 \mathrm{~K}$. The boundary conditions of the hydrogen tested in our study are illustrated in Table 1. Case I is the reference, and cases II, III and IV are used to discuss the effects of the injection pressure and temperature on the combustion flow field of the typical strut-based scramjet combustor.

To investigate the combustion flow field of this model, the two-dimensional coupled implicit RANS equations, the SST $k$ - $\omega$ turbulence model and the finite-rate/eddy-dissipation reaction model are used to numerically simulate the strut-based scramjet combustor. The RANS equations are selected because they can solve on coarser meshes and permit the simplification of steady flow when compared with other numerical methods, namely detached eddy simulation, large eddy simulation and direct numerical simulation [26]. In the investigation, the separated flows are of primary interest. The Menter SST model is preferred because it is substantially more accurate than the $k$ - $\omega$ model for the separated flow case [26]. Furthermore, because of the intense turbulent combustion effect, the finite-rate/eddy-dissipation reaction model is adopted, which can be used to capture the wave behavior and predict the location of the wave system in the combustion flow field [15]. The chemical rate equations are used to model any number reaction occurring in the system. The reaction rates are calculated using the Arrhenius equation [14],

$$
k=A_{\mathrm{p}} T^{N} \mathrm{e}^{\left(-T_{\mathrm{a}} / T\right)},
$$

where $k$ is the reaction rate coefficient, $A_{\mathrm{p}}$ is the pre-exponential factor, $T_{\mathrm{a}}$ is the activation temperature and $N$ is the temperature exponent.

$A_{\mathrm{p}}, T_{\mathrm{a}}$ and $N$ are determined experimentally for a particular reaction. Two different hydrogen-air reaction mechanisms

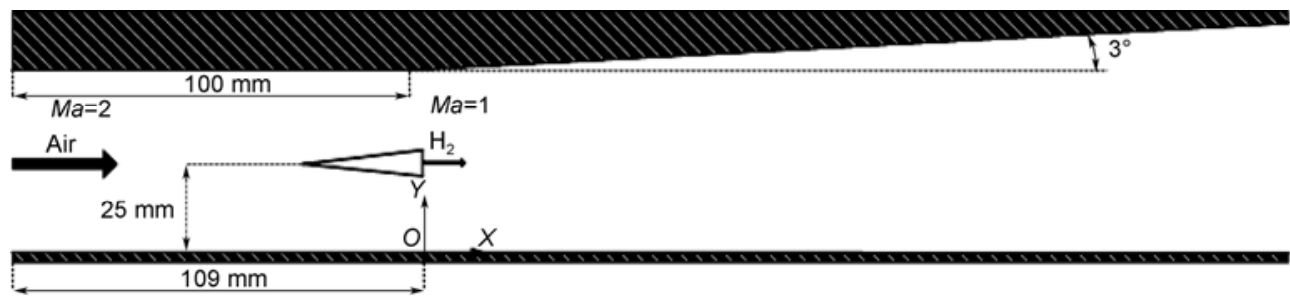

Figure 1 A schematic of a typical strut-based scramjet combustor. 
Table 1 Boundary conditions employed in the model

\begin{tabular}{ccllll}
\hline \multirow{2}{*}{ Parameters } & \multirow{2}{*}{$\begin{array}{c}\text { Supersonic } \\
\text { incoming flow }\end{array}$} & \multicolumn{5}{c}{ Injection } \\
\cline { 3 - 6 } & I & II & III & IV \\
\hline$T_{\mathrm{e}}(\mathrm{K})$ & 340 & 1.0 & 1.0 & 1.0 & 1.0 \\
$P_{\mathrm{e}}(\mathrm{Pa})$ & 100,000 & 100000 & 100000 & 506625 & 506625 \\
$Y_{\mathrm{O}_{2}}$ & 0.232 & 0 & 0 & 0 & 0 \\
$Y_{\mathrm{N}_{2}}$ & 0.736 & 0 & 0 & 0 & 0 \\
$Y_{\mathrm{H}_{2} \mathrm{O}}$ & 0.032 & 0 & 0 & 0 & 0 \\
$Y_{\mathrm{H}_{2}}$ & 0 & 1.0 & 1.0 & 1.0 & 1.0 \\
\hline
\end{tabular}

are used in this paper, namely the one- and the two-step mechanisms of Rogers and Chinitz [27], with rate parameters according to Table 2. While a no-slip condition is applied along the wall surface, at the outflow all the physical variables are extrapolated from the internal cells because the flow is supersonic [28].

The computational grids are structured and generated by the commercial software Gambit, and the total number of cells is about 42000 . The grids are distributed more densely near the walls to resolve the boundary layer [29].

\section{Results and discussion}

Figure 2 shows the comparison between the numerical results and the experimental data. The numerical results are obtained using the one-step hydrogen-air reaction mechanism. An expansion wave fan is generated at the transitional point between the upper wall and the base face of the strut, and another one is formed at the transitional point between the lower wall and the base face of the strut. They are nearly symmetric according to the center line of the strut, although the geometric configuration of the combustor is not symmetric because of the small divergent angle on its upper wall. Because of the wave reflection between the upper and lower walls, several diamond waves are formed after the base face of the strut (Figure 2(a)). At the same time, two obvious shear layers are generated between the supersonic incoming flow and the fuel injection because of the horizontal fuel injection at the center of the base face of the strut (Figure 2(b)-(d)). The combustion occurs intensively in the vicinity of the base face of the strut because of the double vorticity generated near the base face (Figure 2(e)). The

Table 2 Rate parameters for the different $\mathrm{H}_{2}$-air mechanisms

\begin{tabular}{lccccc}
\hline Mechanism & No. & Reaction & $A_{\mathrm{p}}\left(\mathrm{m}^{3} / \mathrm{kmol} \mathrm{s}\right)$ & $N$ & $T_{\mathrm{a}}(\mathrm{K})$ \\
\hline One-step & 1 & $\mathrm{H}_{2}+1 / 2 \mathrm{O}_{2}-\mathrm{H}_{2} \mathrm{O}$ & $9.87 \times 10^{8}$ & 0 & $3.1 \times 10^{7}$ \\
Two-step [27] & 1 & $\mathrm{H}_{2}+\mathrm{O}_{2}-\mathrm{OH}+\mathrm{OH}$ & $2.30 \times 10^{16}$ & 0 & 5134 \\
& 2 & $2 \mathrm{OH}+\mathrm{H}_{2}-2 \mathrm{H}_{2} \mathrm{O}$ & $1.83 \times 10^{18}$ & 0 & 11067 \\
\hline
\end{tabular}
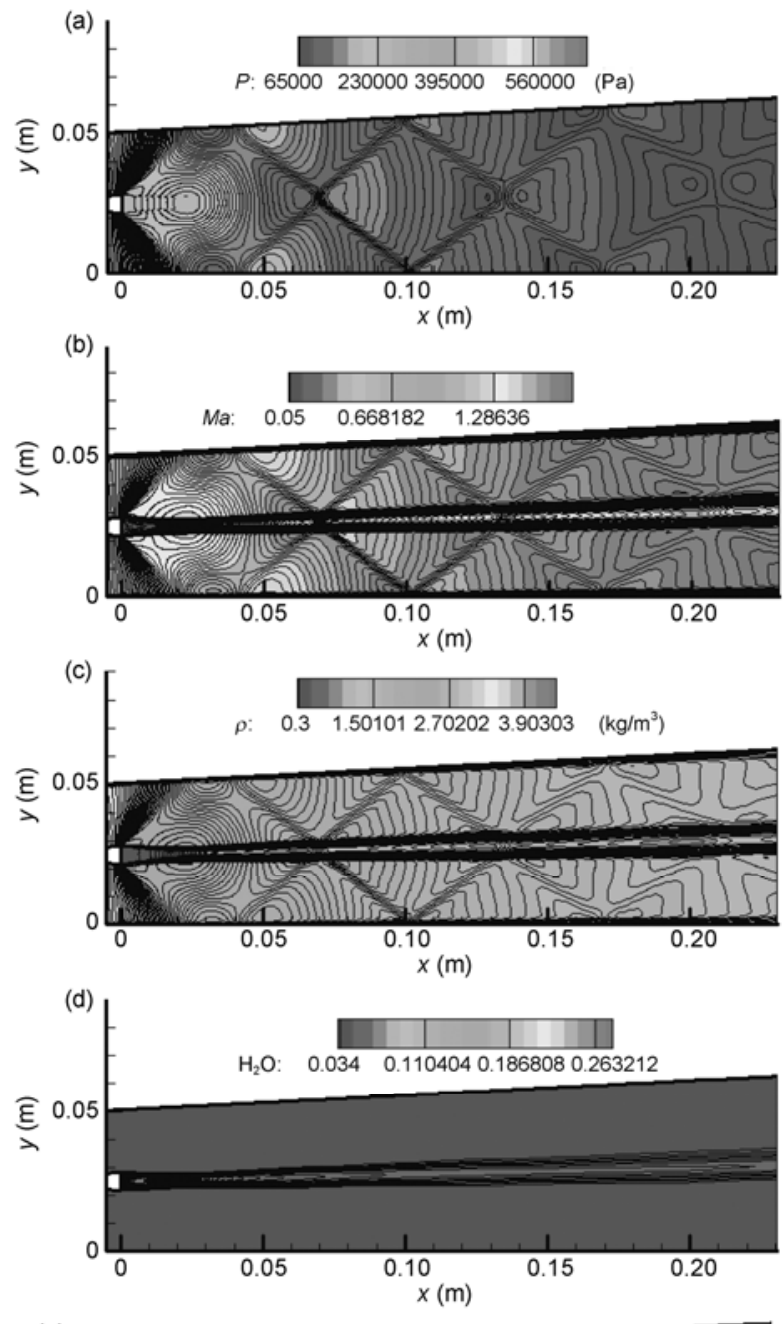

(e)
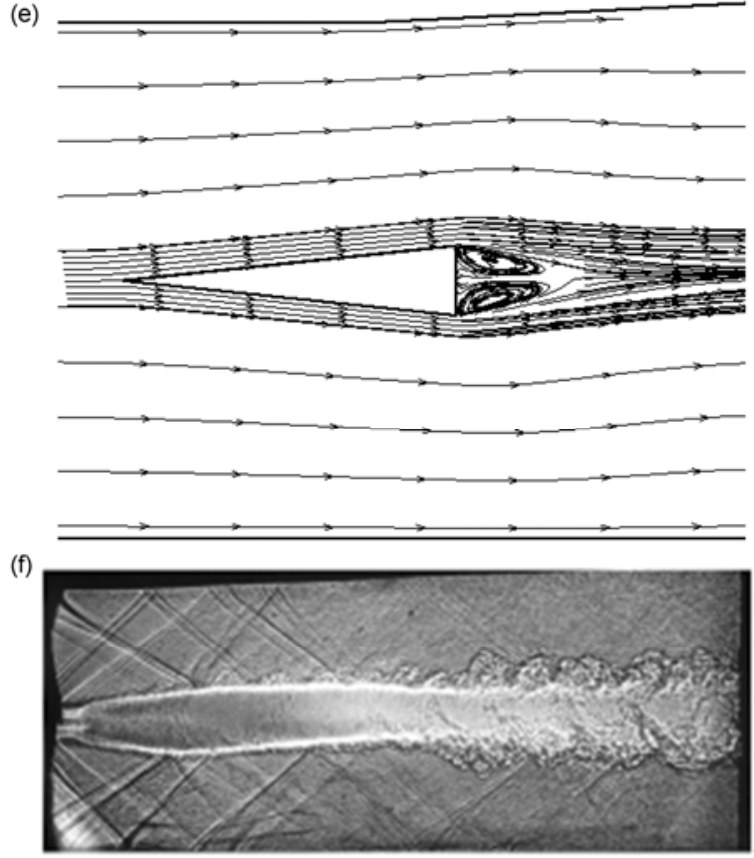

Figure 2 Comparison between the numerical results and the experimental data. (a) Static pressure; (b) Mach number; (c) density; (d) $\mathrm{H}_{2} \mathrm{O}$ mass fraction; (e) local streamline path; (f) experimental shadowgraph. 
reaction zone of the numerical results is narrower than that of the experimental data because of the difference in injection pressure between the numerical simulation and the experiment, and the inaccuracy of the turbulence model or the two-dimensional assumption (Figure 2(f)). Therefore, the results show reasonable qualitative agreement with the experimental data, and the numerical method employed in this paper can be reasonably used to capture the wave system in the combustor.

Figure 3 shows the comparisons of the parametric distributions along the upper and lower walls of the combustor with the two hydrogen-air reaction mechanisms. The hydrogen-air reaction mechanism makes only a slight difference to the static pressure and Mach number distributions along the upper and lower walls of the combustor except in the region of the first pressure drop. We also observe that the expansion waves and the shock waves exist simultaneously in the flow field of the combustor. The expansion wave is generated just ahead of the shock wave in each circular, and the intensities of the expansion wave and the
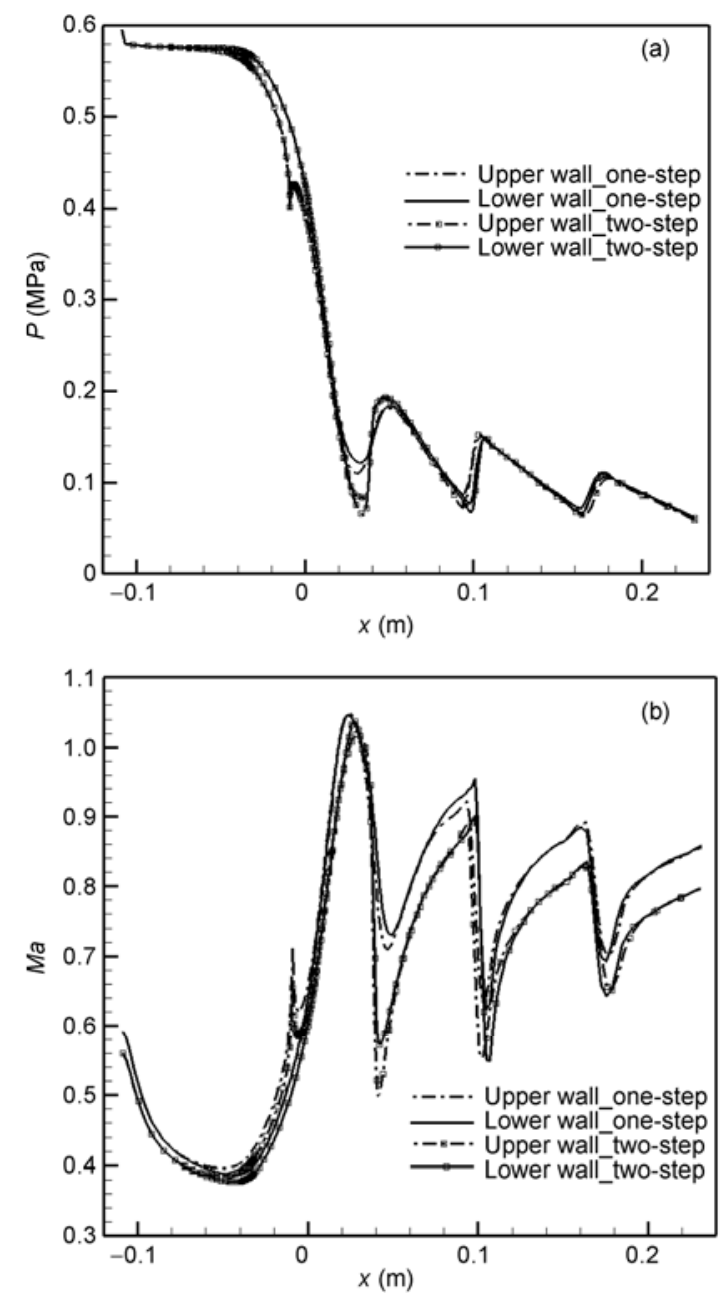

Figure 3 Comparisons of the parametric distributions along the walls of the combustor with different hydrogen-air reaction mechanisms under the boundary condition I. (a) Static pressure; (b) Mach number. shock wave decrease gradually (Figure 3(a),(b)). There are three shock waves and four expansion waves formed in the combustor. Because there is a small divergent angle on the upper wall of the combustor, a weak expansion wave is generated in this region. A pressure drop and Mach number rise occur at $X=-9 \mathrm{~mm}$ on the parametric distribution along the upper wall (Figure 3(a),(b)). This is the main origin for the wave system variance in the combustor.

Figures 4 and 5 show the comparisons of the static pressure and Mach number distributions along the walls of the combustor under the different fuel injection conditions. We observe that the static pressure and Mach number distributions along the upper and lower walls are almost the same under the same fuel injection conditions. When the injection pressure or temperature increases, it seems that a back pressure is located at the end of the channels generated between the walls of the strut and the combustor. The waves have been pushed forward, and the diamond wave systems disappear (Figure 6). Figure 6 shows the static pressure contours of the scramjet combustor under the different fuel
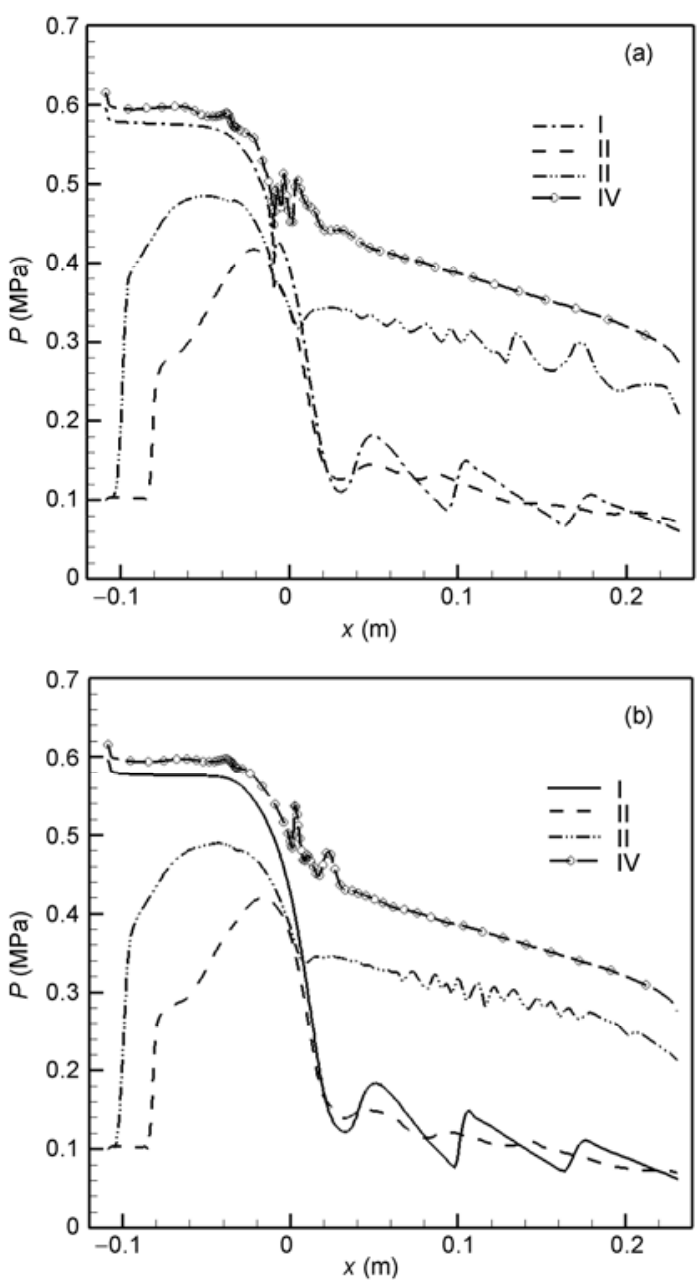

Figure 4 Comparisons of the static pressure distributions along the walls of the combustor under the different boundary conditions. (a) Upper wall; (b) lower wall. 

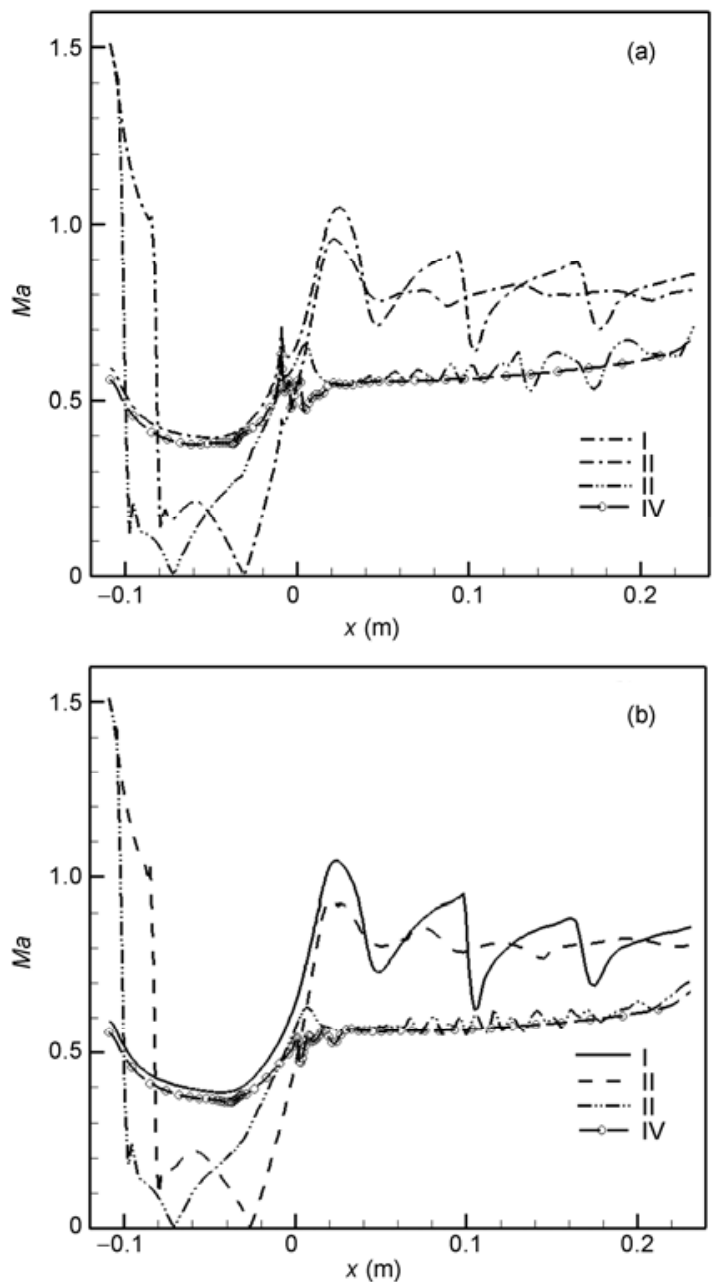

Figure 5 Comparisons of the Mach number distributions along the walls of the combustor under the different boundary conditions. (a) Upper wall; (b) lower wall


Figure 6 Static pressure contours of the scramjet combustor under different fuel injection conditions. (a) Case II; (b) case III; (c) case IV. injection conditions. Furthermore, the separation zone occurs in double when the injection temperature or pressure varies (Figure 7), and the separation zone of case II is larger than that of case III. The separation zone is formed because of the interaction between the shock wave and the boundary layer, and the interaction is weaker and the separation smaller after the wave transition. Figure 7 shows the Mach number contours of the scramjet combustor under the different fuel injection conditions.

When the injection temperature increases, namely case II, the shock waves are generated in the vicinity of the walls of the combustor. A normal shock wave is formed ahead of the strut (Figure 6(a)), and a pressure rise occurs in front of the strut (Figure 4). In case III, when the injection pressure increases, the shock waves evolve into the normal shock wave and the wave system is pushed further forward (Figure 6(b)). This means that the injection pressure is more important than the injection temperature for wave transition. The expansion waves are much weaker, leading to the larger static pressure and Mach number distributions after the base face of the strut (Figures 4-7). At the same time, when the injection pressure increases, there is a disturbance on the static pressure distribution along the walls (Figure 4). When the injection temperature and pressure both increase, namely case IV, the disturbance is pushed forward just in the vicinity of the base face of the strut.

Increasing the injection temperature and pressure makes the reaction zone broader than with the initial injection condition (Figure 7), namely case I. The expansion waves generated at the transitional point of the strut disappear gradually because of the wave transition in the combustor (Figure 6). When the injection temperature and pressure both increase, the waves are pushed out of the combustor, and the


Figure 7 Mach number contours of the scramjet combustor under different fuel injection conditions. (a) Case II; (b) case III; (c) case IV. 
air flows into the combustor with subsonic velocity (Figure $7(\mathrm{c})$ ). The reaction zone at the exit of the combustor is nearly half of the area. From this trend, we observe that the fuel injection temperature and pressure are the main origin for the wave transition in the scramjet combustor, and they affect the parametric distributions in the boundary layer.

\section{Conclusion}

We have used the two-dimensional coupled implicit RANS equations, the SST $k$ - $\omega$ turbulent model and the finite-rate/ eddy-dissipation reaction models to investigate the parametric effects on the combustion flow field of a typical strutbased scramjet combustor, namely the injection pressure and temperature. The one- and two-step hydrogen-air reaction mechanisms were both introduced to simulate the combustion flow field. We conclude the following:

(1) The numerical methods employed in this paper can be used to capture the wave systems in the typical strut-based scramjet combustor, and the results show good qualitative agreement with the experimental data. The major cause of the discrepancy may be the slight difference in fuel injection pressure between the numerical simulation and the experiment or the inaccuracy of the turbulence model.

(2) The hydrogen-air reaction mechanism used in this paper makes only a slight difference to the parametric distributions along the walls of the combustor, and the complex reaction mechanism can provide more information on the flow field in the combustor.

(3) A disturbance occurs in the combustor as the injection pressure increases. When the injection pressure and temperature both increase, the disturbance location moves forward in the vicinity of the base face of the strut. This can strengthen the combustion in the scramjet combustor.

(4) Under the initial injection conditions, diamond waves are generated in the combustor, and the expansion waves and the shock waves exist simultaneously. Furthermore, the expansion waves are formed ahead of the shock waves. When the injection conditions vary, a transition occurs from the shock wave to the normal shock wave, and the separation zone is generated in double near the walls of the combustor. When the injection temperature and pressure both increase, the waves are pushed out of the combustor, and the flows in the combustor are with subsonic velocity.

The authors would like to thank the reviewers for their constructive suggestions on the paper. This work was supported by the National Natural Science Foundation of China (90816027 and 61004094), the Excellent Graduate Student Innovative Project of the National University of Defense Technology (B070101), the Hunan Provincial Innovation Foundation for Postgraduate (3206) and the Chinese Scholarship Council (2009611036).

1 Voland R T, Huebner L D, McClinton C R. X-43A hypersonic vehicle technology development. Acta Astronaut, 2006, 59: 181-191
2 Huang W, Pourkashanian M, Ma L, et al. Investigation on the flameholding mechanisms in supersonic flows: Backward-facing step and cavity flameholder. J Visual, 2011, 14: 63-74

3 Huang W, Luo S B, Wang Z G. Key techniques and prospect of nearspace hypersonic vehicle (in Chinese). J Astronaut, 2010, 31: 12591265

4 Huang W, Qin H, Luo S B, et al. Research status of key techniques for shock-induced combustion ramjet (shcramjet). Sci China Tech Sci, 2010, 53: 220-226

5 Gerlinger P, Stoll P, Kindler M, et al. Numerical investigation of mixing and combustion enhancement in supersonic combustors by strut induced streamwise vorticity. Aerosp Sci Technol, 2008, 12: 159-168

6 Zou J F, Zheng Y, Liu O Z. Simulation of turbulent combustion in DLR Scramjet. J Zhejiang Univ-Sc A, 2007, 8: 1053-1058

7 Oevermann M. Numerical investigation of turbulent hydrogen combustion in a SCRAMJET using flamelet modeling. Aerosp Sci Technol, 2000, 4: 463-480

8 Kumaran K, Behera P R, Babu V. Numerical investigation of the supersonic combustion of kerosene in a strut-based combustor. J Propul Power, 2010, 26: 1084-1091

9 Genin F, Menon S. Simulation of turbulent mixing behind a strut injector in supersonic flow. AIAA J, 2010, 48: 526-539

10 Berglund M, Fureby C. LES of supersonic combustion in a scramjet engine model. P Combust Inst, 2007, 31: 2497-2504

11 Berglund M, Fedina E, Fureby C, et al. Finite rate chemistry largeeddy simulation of self-ignition in a supersonic combustion ramjet. AIAA J, 2010, 48: 540-550

12 Luo S B, Huang W, Pourkashanian M, et al. Investigation of turbulent models for the flow field from a typical strut-based scramjet combustor. Proceedings of ASME Turbo Expo 2011, Vancouver, Canada, 2011

13 Li J G, Yu G, Zhang Y, et al. Experimental studies on self-ignition of hydrogen/air supersonic combustion. J Propul Power, 1997, 13: 538542

14 Engman E. Numerical simulation of scramjet combustion. Master's Degree. Sweden: Lulea University of Technology, 2008

15 Huang W, Luo S B, Liu J, et al. Effect of cavity flame holder configuration on combustion flow field performance of integrated hypersonic vehicle. Sci China Tech Sci, 2010, 53: 2725-2733

16 Huang W, Luo S B, Pourkashanian M, et al. Numerical simulations of typical hydrogen fueled scramjet combustor with a cavity flameholder. The 2010 International Conference of Mechanical Engineering, London, UK, 2010

17 Gu H B, Chen L H, Chang X Y. Experimental investigation on the cavity-based scramjet model. Chinese Sci Bull, 2009, 54: 2794-2799

18 Kim K M, Baek S W, Han C Y. Numerical study on supersonic combustion with cavity-based fuel injection. Int $\mathrm{J}$ Heat Mass Tran, 2004, 47: 271-286

19 Takahashi S, Yamano G, Wakai K, et al. Self-ignition and transition to flame-holding in a rectangular scramjet combustor with a backward step. P Combust Inst, 2000, 28: 705-712

20 Halupovich Y, Natan B, Rom J. Numerical solution of the turbulent supersonic flow over a backward facing step. Fluid Dyn Res, 1999, 24: 251-273

21 Luo S B, Huang W, Lei J, et al. Drag force characteristic of a typical dual-mode scramjet combustor. The 2010 International Conference on Mechanical and Aerospace Engineering (CMAE 2010), Chengdu, China, 2010

22 Zhao Z, Song W Y, Xiao Y L, et al. An experimental investigation of the cold flowfield in a model scramjet combustor. P I Mech Eng G-J Aer, 2009, 223: 425-431

23 Yu G, Li J G, Zhang X Y, et al. Experimental investigation on flameholding mechanism and combustion performance in hydrogen-fueled supersonic combustors. Combust Sci Technol, 2002, 174: $1-27$

24 Hsu K Y, Carter C D, Gruber M R, et al. Experimental study of cavitystrut combustion in supersonic flow. J Propul Power, 2010, 26: 1237-1246 
25 Huang W, Pourkashanian M, Wang Z G, et al. Overview of fuel injection techniques for scramjet engines. Proceedings of ASME Turbo Expo 2011, Vancouver, Canada, 2011

26 Zingg D W, Godin P. A perspective on turbulence models for aerodynamic flows. Int J Comput Fluid D, 2009, 23: 327-335

27 Rogers R C, Chinitz W. On the use of hydrogen-air combustion model in the calculation of turbulent reacting flows. AIAA Paper
1982-0112, 1982

28 Huang W, Wang Z G, Pourkashanian M, et al. Numerical investigation on the shock wave transition in a three-dimensional scramjet isolator. Acta Astronaut, 2011, 68: 1669-1675

29 Tohru M, Toshinori K. Flame structures and combustion efficiency computed for a Mach 6 scramjet engine. Combust Flame, 2005, 142: $187-196$

Open Access This article is distributed under the terms of the Creative Commons Attribution License which permits any use, distribution, and reproduction in any medium, provided the original author(s) and source are credited. 